\title{
EL IMPACTO DE LAS NUEVAS TECNOLOGÍAS EN LAS PERSPECTIVAS DEL PAISAJE \\ Liliana Quintero*
}

\section{THE IMPACT OF NEW TECHNOLOGIES \\ ON THE NOTION OF LANDSCAPE}

RESUMEN: El concepto de paisaje ha cambiado, se ha hecho más amplio gracia a la tecnología, transita de lo natural a lo artificial. Y más allá de la pantalla surge la arquitectura cyborg: dispositivos digitales como plataforma creativa; una nueva experiencia, el no-lugar, pero también nuevos riesgos.

PALABRAS CLAVE: paisaje, pantalla, dispositivos digitales, no-lugar, intervención.
ABSTRACT: The concept of landscape has changed. Becoming more extensive due to technology, it evolves from the natural to the artificial. And from beyond the screen emerges cyborg architecture: digital devices utilized as creative platforms: a new experience, the non-place, as well as new risks.

KEYWORDS: landscape, screen, digital devices, non-place, intervention.

RECEPCIÓN: 28 de enero de 2014.

ACEPTACIÓN: 12 de diciembre de 2014.

* Facultad de Filosofía y Letras, UNAM. 


\section{EL IMPACTO DE LAS NUEVAS TECNOLOGÍAS EN LAS PERSPECTIVAS DEL PAISAJE}

Reflexionar acerca del paisaje se torna problemático, ya que cuando nos referimos a éste, en abstracto, resulta difícil definirlo. El paisaje implica un componente humano, un observador, pero también implica un territorio determinado. Desde la óptica de la geografía se observa una relación de tierra, de cierta organicidad que se vincula con el ojo de un espectador, de un habitante. El término Landscape, se traduce como una forma de tierra, una forma de suelo. ${ }^{1}$ Pero, ¿qué sucede cuando ese suelo se escapa de los límites físicos? Finalmente el paisaje es un concepto y ya no podemos hablar de un paisaje totalmente natural, siempre existe una fisura técnica que impregna sus elementos y brotan huellas de artificialidad. ${ }^{2}$

Pero en nuestro imaginario, cuando hablamos de paisaje se refleja el espíritu que nos heredaron los románticos y se abre un interés por rescatar la idea que encierra el paisaje natural; nos intriga porque representaba la otredad, el inconsciente, el impulso, el misterio, la fuerza creadora, el Sturm und Drang. ${ }^{3}$

${ }^{1}$ Carl O Sauer, "La morfología del paisaje”, 2 de junio 2013 (http://polis.revues.org/5015).

${ }^{2}$ Concepto usado por Fernando Broncano y Jorge Linares.

${ }^{3}$ Concepto utilizado por los románticos como ruptura frente al dominio de la razón, se traduce como tormenta e ímpetu. 


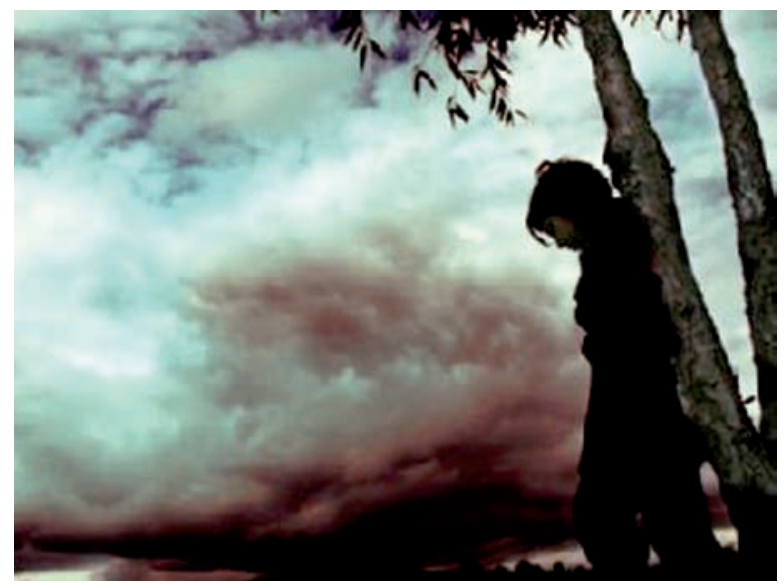

En este sentido, Amaranta Sánchez retoma la mirada romántica, en homenaje, y crea la obra Sturm und Drang, en la que observa desde otro ángulo y retoma el paisaje, pero con el interés de modificar lo estable y así interviene el espacio orgánico para dislocarlo en un espacio onírico; la mirada de la artista reflexiona en elementos como la luz artificial, la imagen invertida, el pliegue repetitivo, el brote de nostalgia y el guiño de tempestad, los cuales se manifiestan como componentes que rompen una estructura lógica para revelar que lo que vemos no es un paisaje, es ficción, que nos remite una búsqueda sobre un paisaje que ha quedado perdido.

\section{Paisaje a-biótico/la mediatización del entorno}

El ser humano es sin duda un animal que se distingue por su manera de crear interfaces, algunos dicen que el lenguaje es la primera interfaz. El humano se define desde su mediación artefactual. Siempre hay algo en medio que le permite interactuar con el entorno; sin duda, esa mediación no sólo es un instrumento que facilita su acontecer, sino que se vuelve parte del mundo, es real, pero tiene una característica primordial, su virtualidad. Aristóteles señaló que lo potencial estaba en estrecha relación con lo actual, que la semilla era potencialmente árbol y que en ésta yacía toda la esencia de llegar a ser actual. Pero Aristóteles no pudo imaginarse que la potencia se materializaría en un estado intermedio. Las cosas se quedan en estado- 
semilla, pero con una posibilidad ficcional, de imagen, en estado numérico, en código, pero quizá el código es su estado actual, lo problemático es que eso se vuelve invisible, porque lo que vemos son imágenes. En la actualidad la virtualidad está adquiriendo un estatus mayor que el estado real y es porque "lo virtual puede ser también una propiedad de la realidad (y de sus objetos físicos)". ${ }^{4}$

Se convierte la realidad, como afirma José Ramón Alcalá, "en algo que nos impide tropezarnos físicamente con ella". ${ }^{5}$ Se despliega de manera fantasmagórica, pero necesita de un artefacto con la cual se agencie, se haga cómplice: la pantalla.

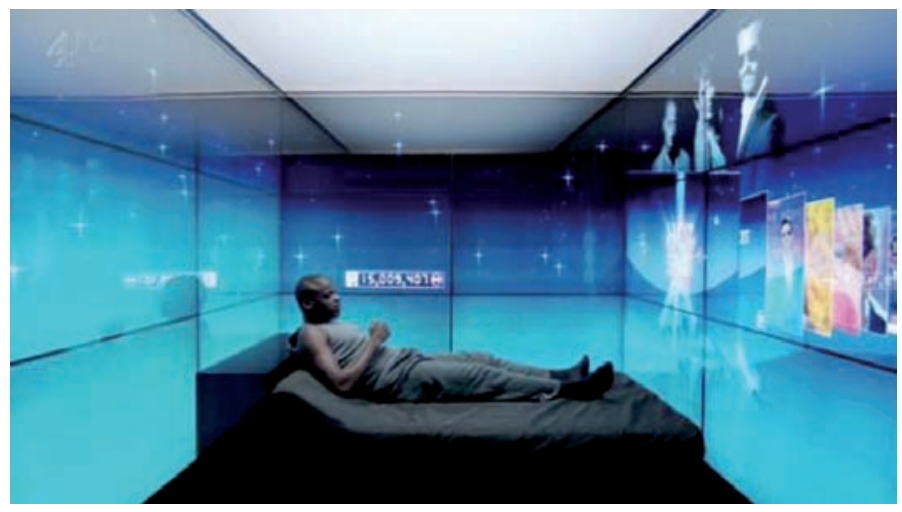

Las pantallas se han convertido en superficies de captura, de escape. Pero, ¿por qué nos resultan tan agradables? De alguna manera, se vuelven ventanas que han sustituido la contemplación del paisaje. Muchas de las ciudades contemporáneas borran sus fronteras con el paisaje natural y han sido invadidas por superficies mediales.

Tokio es un buen ejemplo de una ciudad medial. Japón se integra muy bien al ciberespacio, por un lado la manera en como Oriente concibe el concepto de espacio, y el otro, que "después de la bomba atómica quedaron orillados a huir al mundo virtual, otaku, en una de sus acepciones significa quedarse en casa, y así lo llevaron a cabo, se quedaron en casa envueltos entre el televisor, los videos y los ordenadores". ${ }^{6}$

${ }^{4}$ José Ramón Alcalá, Ser digital. Manual de supervivencia para conversos a la cultura electrónica, 2009, Santiago, AV Ediciones del Departamento de Artes Visuales, p. 17.

${ }^{5}$ Idem.

${ }^{6}$ Marc Augé, "Sobre modernidad: del mundo tecnológico de hoy al desafío esencial del mañana", Dênis de Moraes, (coord), Sociedad mediatizada, 2007, Barcelona, Gedisa, p. 127. 


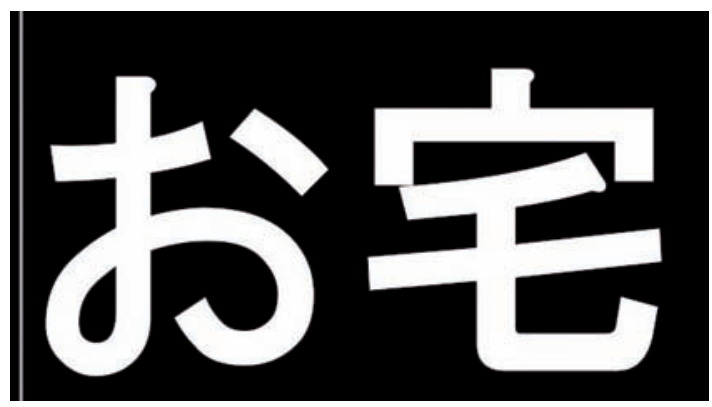

Hervé Le Bras afirma que vivimos en "la era de la extensión urbana". ${ }^{7}$ Las ciudades crecen y se tragan el paisaje, creando horizontes distorsionados, llenos de ruido, de contaminación visual, nos invaden las pantallas publicitarias: en el metro, en la calle, en los bares, en el tránsito; y no contentos con ello, cada individuo huye de la cartografía pantalicus ${ }^{8}$ abriendo su propia ventana personal desde un teléfono, un iPod, un iPad, una iTablet, un ordenador, un PSP, un android o unos google glass.

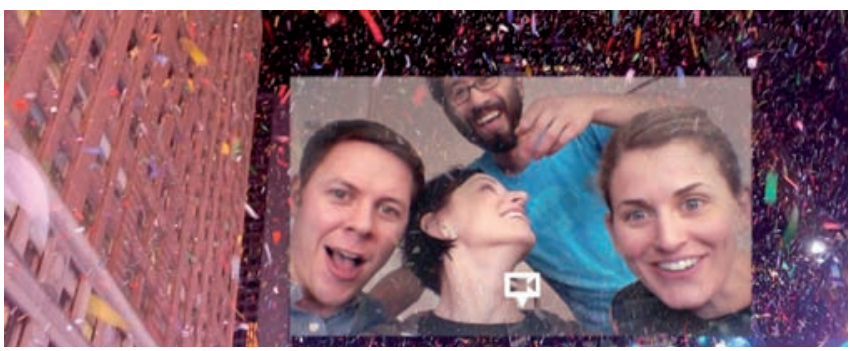

El problema de las pantallas es que no las controlamos, aparecen, se despliegan, las portamos a todo momento, y a su vez, ellas nos portan.

Quizá una manera de huir de las pantallas es la intervención estética, una pieza sugerente es

The Artvertiser ${ }^{9}$ de Julian Oliver, dispositivo de visualización que permite reemplazar (virtualmente) el contenido de un cartel o valla publicitaria por cualquier otro que se desee (imágenes, vídeo). En primer lugar, el artista

${ }^{7}$ Marc Augé, op. cit., p. 130.

${ }^{8}$ Término utilizado por Lipovetsky y Jean Serroy, refiriéndose al homo pantalicus, en Gilles Lipovetsky y Jean Serroy, La cultura-mundo, 2010, Barcelona, Anagrama, p. 85.

${ }^{9}$ Julian Oliver, The Artvertiser, 2008. 
NOTAS

"enseña" al ordenador a reconocer determinados anuncios como espacios a ser intervenidos y posteriormente invita a otros artistas a crear contenidos para aplicarlos en el lugar predefinido. Por medio de un dispositivo de visualización, se pueden observar dichos espacios intervenidos. El artista habla en este proyecto de "realidad mejorada", más que "aumentada", puesto que su proyecto intenta contrarrestar la invasión del paisaje urbano por parte de las corporaciones. ${ }^{10}$

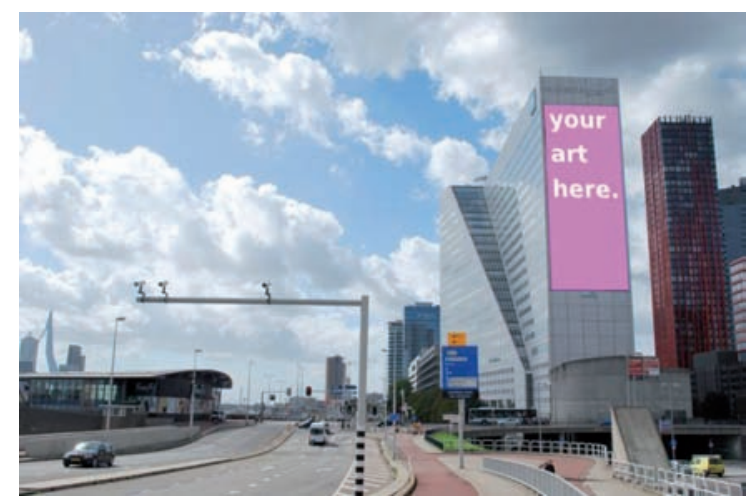

Otra manera de intervención-acción es lo que realiza el colectivo Kònic Thtr:

Una de sus obras, Before the beep, pieza escénica, hace referencia a los cambios de la percepción humana en la comunicación interpersonal mediada por las nuevas tecnologías y a los espacios que esta mediación genera. La pieza confronta el cuerpo con estas mismas tecnologías mediadoras de la comunicación y explora cómo éstas re-escriben el cuerpo y cambian nuestra comprensión de lugar y la idea de presencia, redefiniendo narrativas e individuos. Before the beep se despliega como una membrana tecnológica que ofrece al público lecturas de la comunicación contemporánea. ${ }^{11}$

${ }^{10}$ Información extraída del sitio oficial de Julian Olivier: The artvertiser: improved reality, 2 de junio 2013 (http://theartvertiser.com/) (La traducción es mía).

${ }^{11}$ Información extraída de Antic Teatre, 2 de junio 2013 (http://www.anticteatre.com/arxius/ Programacio_anual_2011/2011_abril_index.html). 


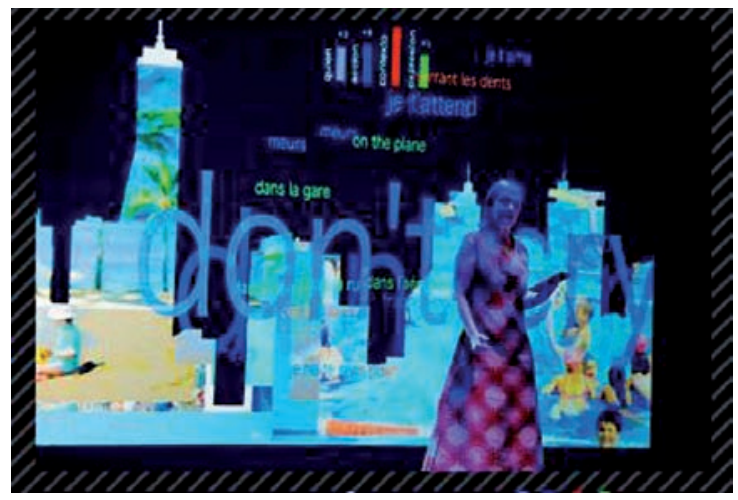

Son dos piezas que nos invitan a reflexionar sobre la exacerbada medialidad de la realidad contemporánea, las dos habitan a los dispositivos tecnológicos desde lo interno, generando reflexiones estéticas, en las que el componente visual es indispensable.

Más allá de la pantalla. Arquitectura-cyborg. Los dispositivos digitales como posibilidad de una plataforma creativa

Internet se ha convertido en un espacio relevante en la actualidad, principalmente las generaciones de adolescentes y jóvenes transitan el mayor tiempo en las atmosferas digitales o se encuentran en el pliegue fronterizo entre las dos. Habitan los dos espacios simultáneamente.

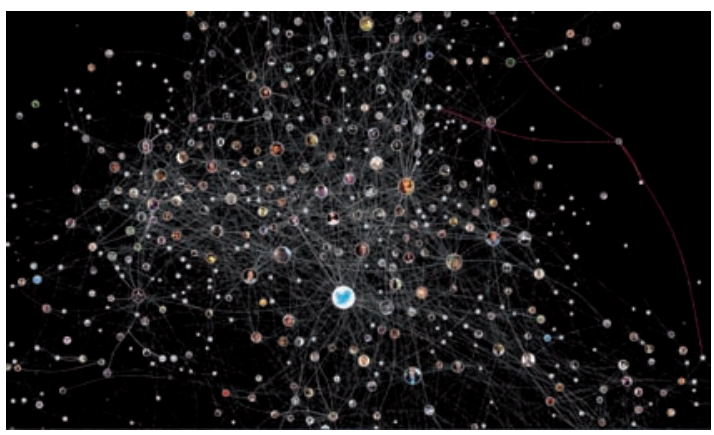


NOTAS

Remedios Zafra en su libro Un cuarto propio conectado reflexiona precisamente en la manera como habitamos el mundo contemporáneo, cuáles son los límites de nuestro espacio y plantea que "ya no son sólo espacios materiales, sino hablamos de una prolongación de la pantalla y su versatilidad de ser un mismo escenario para usos diversos". ${ }^{2}$

En este sentido es a lo que José Pérez Lama ${ }^{13}$ se refiere como arquitectura cyborg, aquella que integra los dos espacios: el físico con el virtual, haciendo múltiples relaciones. Aunque se vuelve un tanto paradójico ya que uno tiene una naturaleza mental, transitoria y no es capaz de soportar o contener arquitectura. "Una página web [...] no ofrece soporte para el cuerpo". ${ }^{14}$

\section{Advertencia}

Me gustaría integrar una reflexión que Derrick de Kerckhove en su libro La piel de la cultura ${ }^{15}$ advierte, dice que el ideograma japonés MA tiene cierta similitud en la manera como se desplaza el concepto de espacio en el ciberespacio, generándose una espacie de fusión entre espacio y tiempo del mismo modo que el concepto japonés, ya que MA es espacio-tiempo no hay una separación, pero también se pueden referir de manera separada al tiempo, y al espacio.

La palabra MA parece a primera vista vaga pero es la multiplicidad de significados y al mismo tiempo lo conciso de una sola palabra lo que hace de $m a$ un término conceptual único sin paralelo en otros idiomas. [...]

MA es importante no solo como una idea abstracta, sino también como un elemento estructural concreto. Para los japoneses es esencial considerar a la mayoría de las composiciones como si estuvieran integradas de una parte expresiva y una parte vacía. ${ }^{16}$

\footnotetext{
${ }^{12}$ Remedios Zafra, Un cuarto propio conectado, 2010, Madrid, Forcala, p. 40.

${ }^{13}$ José Ramón Alcalá, La piel de la imagen, 2011, Valencia, Sedemà, p. 144.

${ }^{14}$ Alcalá, Ser digital, op. cit., p. 99.

${ }^{15}$ Alcalá advierte esta referencia en ibid., p. 130.

${ }^{16}$ Kunio Komaparu, “Teatro Noh: Principios y Perspectivas”, en Artes escénicas del japón, 2 de junio 2013 (http://www.japonartesescenicas.org/teatro/generos/simbologiadelnoh7-1.html).
} 


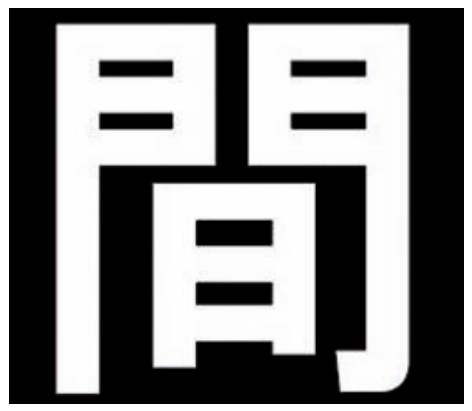

\section{Fin de la Advertencia}

De esta manera, podemos hacer una analogía del paisaje contemporáneo como una suerte de integración del espacio físico y el virtual. Vivimos las dos esferas de realidad, pero no somos conscientes. Es más fácil develarlo bajo la óptica de los artistas, por ejemplo:

El colectivo Les Liens Invisibles realiza proyectos en los cuales les interesa intervenir los espacios y hacen uso de los medios digitales para integrar esferas virtuales en lugares concretos. Una de sus obras consiste en invitar a diversos artistas a crear "pabellones virtuales" que se colocaron en los espacios reservados a los pabellones reales de la Bienal de Venecia (los Giardini) y en la Plaza de San Marcos. El proyecto se presentó como una "experiencia de realidad aumentada no invitada, experimental y alucinatoria". ${ }^{17}$

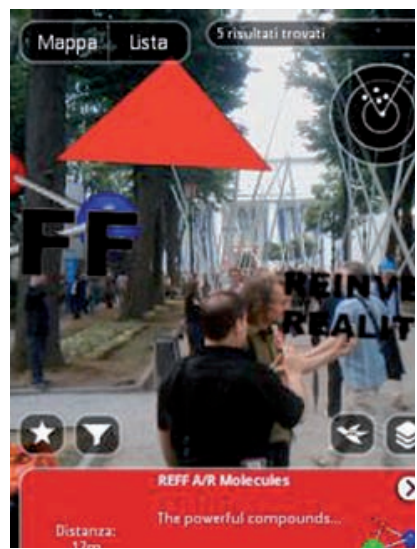

${ }^{17}$ Información consultada del sitio oficial de Les Liens Invisibles: 2 de junio 2013, (http://www. lesliensinvisibles.org/) (La traducción es mía). 
Los dispositivos digitales permiten una nueva forma de experiencia, implican una mediación, pero la mediación se convierte en la experiencia relevante, uno va a un sitio y ya no importa la presencia física, sino lo que interesa es la apariencia, la foto adquiere una nueva modalidad: ya no es la foto del recuerdo, la foto ya no implica un pasado, sino es el instante eterno del presente, del escenario cambiante. Los conciertos, los no-lugares, los lugares, cualquier reunión implica una conexión con un espacio-íntimocolectivo de un perfil, de un perfil establecido, acartonado siempre, muestra el mejor ángulo. No cabe la tristeza, no caben los fluidos corporales, no cabe el tacto, no cabe el cara a cara.

El no lugar, como lo llamo Marc Augé, se ha convertido en la estancia favorita de los individuos contemporáneos. Las ciudades se edifican bajo una lógica homogénea desplazando cada vez más a los lugares, los espacios simbolizados, aquellos espacios que para la antropología nos identificaban, lo que nos permitía reconocernos como comunidad. ${ }^{18}$ Ahora nos reconocemos en la pantalla de internet, somos una multitud conectada, pero destinada a habitar un no-espacio, un espacio líquido. ${ }^{19}$ Hemos perdido interés por movernos y tomar conciencia de un territorio, ocupar un paisaje, navegarlo, caminarlo, construirlo. Somos habitantes del ciberespacio, pero nunca podrá ser un "territorio de reconocimiento, ahí no podremos leer en parte en su totalidad la identidad de los que lo ocupan". ${ }^{20}$

164 Pero siempre se generan grietas, fisuras en las cuales podemos intervenir de otra manera. En este sentido, podemos iniciar una nueva forma de entender el espacio-tiempo fundado desde el ciberespacio. Aunque el paisaje virtual nos habita, nos pone a circular bajo su lógica. Uno de los problemas es que el mundo virtual oculta su materialidad y refleja una distinta; en este sentido es necesario que actúe la mirada del especialista, la intervención artística-tecnológica. Hoy en día "dichas extremidades corporales están también protésicamente digitalizadas en nuestro cerebro". ${ }^{21}$ Quizá ese sea el mayor problema, hemos creado un dispositivo que difícilmente vamos a poder quitar, borrarlo. Günther Anders advirtió que el problema era que "la producción técnica ha situado en las antípodas la reproducción natural de la vida, y que se ha vuelto un proceso ciego y no calculado, Prometeo

${ }^{18}$ Cfr., Marc Augé, op. cit.

${ }^{19}$ Conceptos utilizados por José Ramón Alcalá, en los cuales se refiere al espacio virtual. Cfr. La piel de la imagen, op. cit.

${ }^{20}$ Ibid., p. 129.

${ }^{21}$ Idem. 
se siente orgulloso de sus objetos técnicos, pero avergonzado de sí mismo, los objetos técnicos lo han humillado".22

Me surge una inquietud al recordar cuando mi hijo me preguntó, al ver un documental sobre animales, que si el animal que veía era verdadero o estaba hecho por computadora.

Respondí con cierta preocupación: "por supuesto que es real". Pero algo me intrigaba en esa pregunta, los niños y los jóvenes de esta generación tienen una cercanía mayor con lo virtual; pero ahora el paisaje natural se ha remplazado y se pone en duda si es real. De hecho, podemos observar ahora animales extintos que los documentales nos presentan, bajo un marco pseudocientífico, seres inexistentes que sólo pueden ser reconstruidos desde la memoria, la ciencia y la imaginación, y otros futuros que presentan hipótesis de fantasía. Sabemos que son virtuales, pero nos interesa ver lo imposible, aunque sólo desde el ámbito aparente. Habrá que preguntarnos honestamente si el mundo que hemos diseñado es tan aterrador que no nos queda más que refugiarnos en su estado virtual, o en el inter, en medio de los dos; pero no será esto un engaño más, porque el paisaje aún palpita.

Así, nos muestra Eiija Liisa Athila su pieza Horizontal, en la que activa la majestuosidad de un abeto; el sonido de las hojas movidas por el viento nos obliga a conectarnos con el paisaje natural, pero al clavar la mirada en las hojas nos enfrentamos a la verticalidad del árbol, lo cual nos estorba, nos confronta y nos recuerda que es una pantalla; también sugiere que la mirada no necesariamente tiene que estar siempre desde la lógica arborescente, pudiera tal vez generarse de manera rizomática.

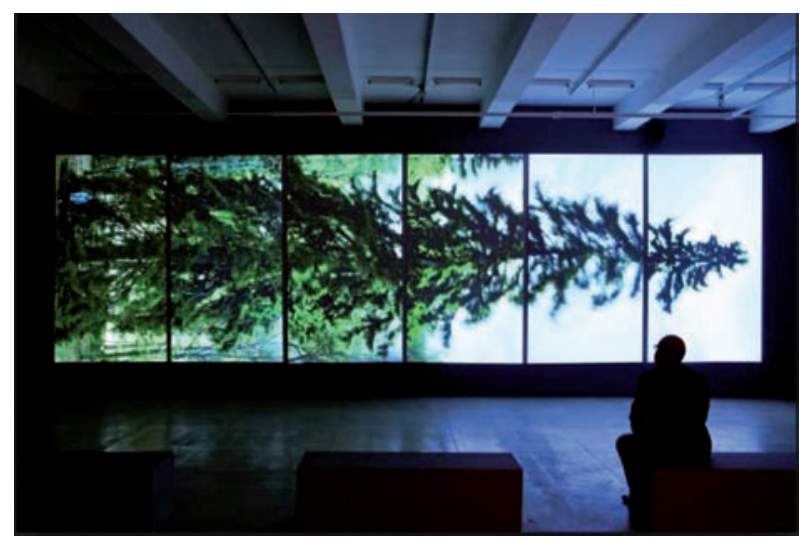

${ }^{22}$ Jorge Linares, Ética y mundo tecnológico, 2007, México, FCE/UNAM, p. 201. 


\section{Paisaje bioartefactual. Límites contemporáneos de inter/vención}

Se habló ya de la intervención medial, de pantallas, de unos y ceros, de imagen, de experiencias fantasmagóricas, de cómo se integra lo virtual en nuestro entorno; me gustaría dibujar un pequeño esbozo de la intrusión tecnocientífica en el paisaje contemporáneo y lo planteo porque la exposición Panorámica lo sugiere como límite final o como otro punto de partida. La pieza de Plantas nómadas de Gilberto Esparza lo advierte.

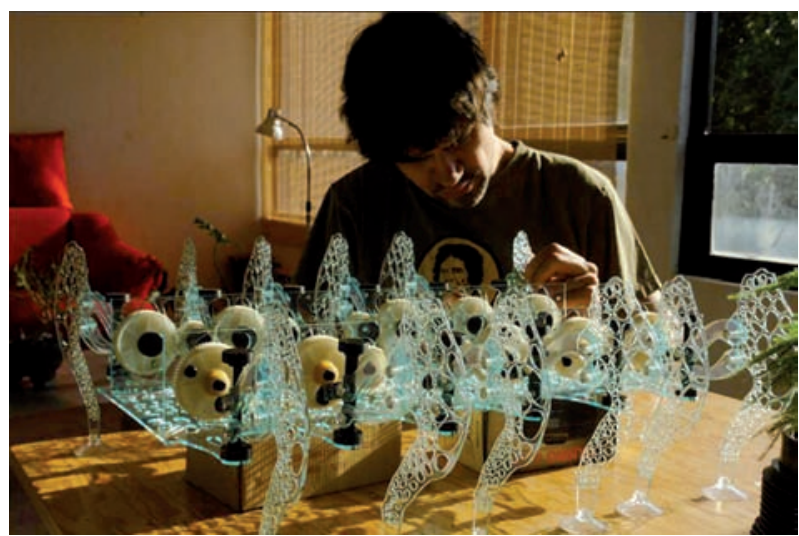

En el entorno contemporáneo, las prácticas tecnocientíficas han desplazado la manera científica de la modernidad y toman como herramienta ejecutante los medios computacionales; esto da como resultado que el dispositivo actúe desde lo íntimo, desde el manejo de información, lo cual modifica de manera molecular, genética e informacional, los elementos vivos. La biotecnología se distingue como la ciencia del siglo XXI, toda la intervención se justifica desde parámetros comerciales y científicos. Robert Carlson reflexiona que la intervención hacia elementos vivos se hace desde parámetros ingenieriles y se van ensamblando como legos: "La ciencia nos ha llevado al punto donde estamos aprendiendo a controlar los elementos moleculares de la vida y el flujo de información entre ellos". ${ }^{23}$

\footnotetext{
${ }^{23}$ Robert H. Carlson, Biology is technology, 2010, Cambridge, Harvard University Press, p. 15 (La traducción es mía).
} 
Otra propuesta interesante es la pieza Desmodium Máquina realizada por el Media lab del Centro Multimedia; es una pieza que intenta rescatar el inconsciente de una planta, a partir del sensado de un ecosistema de plantas que mide la catidad de $\mathrm{CO} 2$, teniendo como factores de intervención la humedad y la temperatura. El ecosistema se comunica con un brazo robótico que, dependiendo de los factores de estímulo, genera una graficación en un disco de cobre. La intención es mostrar, de manera metafórica, la respiración de las plantas, generando una gráfica a partir de las técnicas del grabado. De manera poética, al colectivo del Media lab le interesaba transgredir y poner sobre la mesa la forma en como se trata el entorno natural pero, a su vez, usar un elemento intangible, como la respiración, y un elemento concreto, el oficio tradicional del grabado, proponiendo un paisaje visual que personifica la vida.

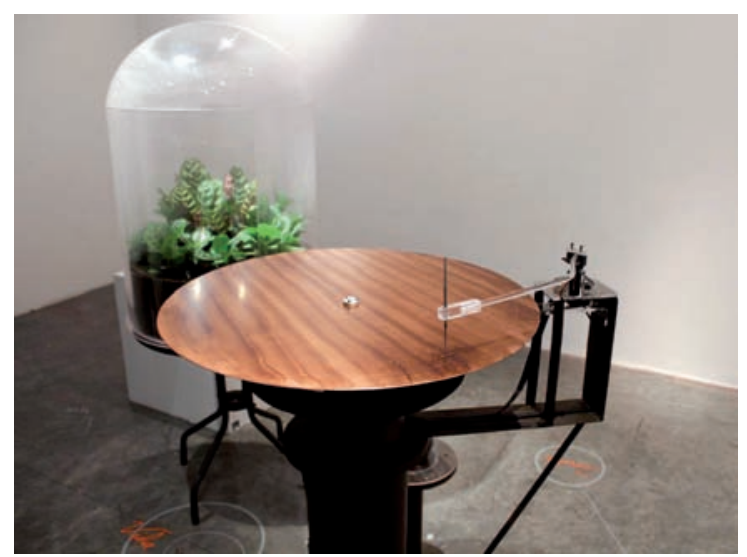




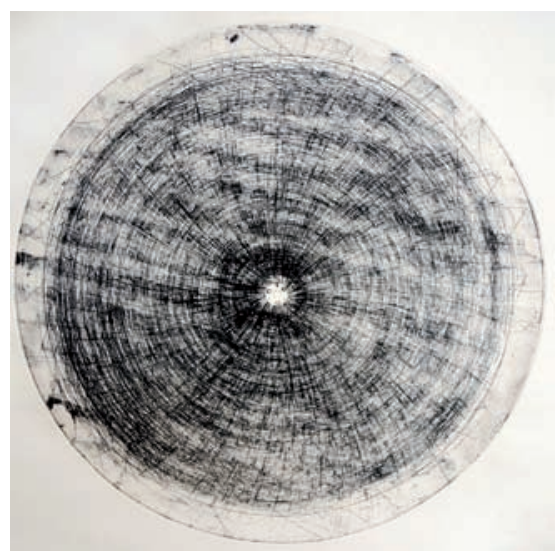

Las prácticas artísticas nos permiten ver lo invisible, pero eso no es suficiente. La tecnociencia se vuelve un dispositivo transgresor que interrumpe, que inter-media el paisaje orgánico, pero la inter-mediación yace invisible. Los laboratorios se tornan en la actualidad como entornos proyectivos para las nuevas especies. Queda claro entonces, que la artificialidad se ha vuelto desproporcionada. Es el momento de apagar nuestras prótesis, nuestras supuestas conexiones y retomar nuestra mejor herramienta, la imaginación; hagamos silencio con ella y tratemos de dibujar-tocar un mundo, un espacio, un lugar, un paisaje posible, aquel que no está en el futuro, pero sí está por venir. ${ }^{24}$
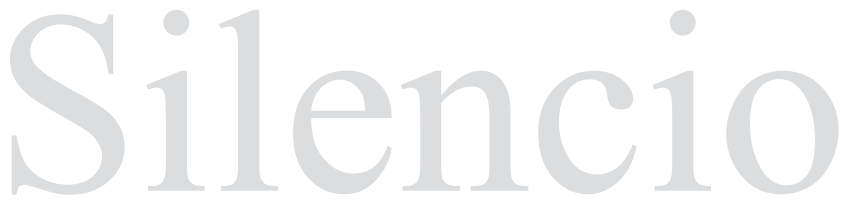

${ }^{24} \mathrm{~A}$ manera de juego y referencia retomo el concepto de por venir de Jacques Derrida, quien distingue el futuro que es algo predecible y lineal, a diferencia del por venir, que es totalmente nuevo; se puede confrontar en: https://www.youtube.com/watch?v=CtcpwJCC6Co. 